17. Jacob H. S., Craddock P. R., Hammerschmidt D. E., and Moldow C. F.: Complement-induced granulocyte aggregation. An unsuspected mechanism of disease. N. Engl. J. Med., 302: 789 (1980).

18. Manroe B. L.. Rosenfeld C. R.. Weinberg A. G., and Browne R.: The differential leukocyte count in the assesment and outcome of early-onset neonatal group B streptococcal disease. J. Pediatr. 91:632 (1977).

19. McCabe W. R.: Serum complement levels in bacteremia due to gram-negative organisms. N. Engl. J. Med., 288: 21 (1973).

20. Pearce M. L.. Yamashita J., and Beazell J.: Measurement of pulmonary edema. Circ. Res.. 16: 482 (1965).

21. Rojas J., Green R. S., Hellerqvist C. G., Olegard R., Brigham K. L.. and Stahlman M. T.: Studies on group B $\beta$-hemolytic streptococcus. Il. Effects on pulmonary hemodynamics and vascular permeability in unanesthetized sheep. Pediatr. Res.. 15: 899 (1981).

22. Sacks T., Moldow C. F., Craddock P. R., Bowers T. K., and Jacob H. S.: Oxygen radicals mediate endothelial cell damage by complement-stimulated granulocytes. An in vitro model of immune vascular damage. J. Clin. Invest.. 61: $1161(1978)$
23. Schalm O. W., Editor: Veterinary Hematology, II Edition. pp. 237-246 (Lea and Febiger, Philadelphia, 1971).

24. Sundell H. W. Gray M. E. Relier J. P., Kovar I. Z., Catterton W. Z.. Swift L. L., and Stahlman M. T.: The effects of ACTH on lung maturation in fetal lambs. AM. J. Pathol.. 97: 393 (1979).

25. This work was done during Dr. Brigham's tenure as an Established Investigator of the American Heart Association

26. We are indebted to Gerda Resch, Patricia Minton, Rao Gaddipati. Fred Morris. Mary Dickie and Nancy Embry for their expert technical assistance and to Diane Peevler for secretarial assistance in the preparation of the manuscript. 27. Fellow supported by the Tennessee Lung Association.

28. Requests for reprints should be addressed to: Dr. Jorge Rojas, Baptist Hospital, 2000 Church Street. Nashville. Tennessee 37236.

29. This research was supported by a grant from the National Institutes of Health HL 22520

30. Received for publication September 3, 1982.

31. Accepted for publication May 20, 1983.

\title{
Interaction between Bovine Casein and $V$. Cholerae Enterotoxin in the Rabbit Ileal Loop
}

\author{
DAVID A. CLARK, ${ }^{(23)}$ RONALD P. PELLEY, AND ALBERT J. SCHNEIDER
}

Division of Neonatology, Department of Pediatrics and Division of Geographic Medicine, Department of Medicine, Case Western Reserve University and University Hospitals, Cleveland, Ohio and Department of Pediatrics, SUNY, Upstate Medical Center, Syracuse, New York, USA

\section{Summary}

Secretory IgA from human breast milk neutralizes cholera enterotoxin in the rabbit ileal loop system. No similar protection by purified bovine milk proteins could be demonstrated; however, one bovine milk protein, casein, had a deleterious effect on intestine exposed to very small quantities of enterotoxin. Highly purified cholera toxin (10 or $100 \mathrm{ng}$ ) was incubated with bovine protein solutions for $60 \mathrm{~min}$ at $37^{\circ} \mathrm{C}$. One-milliliter aliquots were then injected into prepared rabbit intestine loops. The animals were sacrificed at $18 \mathrm{~h}$ and the intestinal loop contents were aspirated, and a volume to length of loop ratio $(\mathrm{V} / \mathrm{L})$ was determined. The activity of $100 \mathrm{ng}$ of toxin was not enhanced by the majority of bovine milk proteins, but bovine casein caused a 14 $40 \%$ increase in the fluid production $(\mathrm{V} / \mathrm{L}$ of casein + toxin versus toxin, 1.05 versus 0.92 and 1.82 versus 1.30 ). All of the bovine proteins but casein inhibited the action of low dose enterotoxin. Bovine casein caused a $78-90 \%$ increase in fluid production by loops exposed to a suboptimal toxin dose $(10 \mathrm{ng})(\mathrm{V} / \mathrm{L}$ of casein + toxin versus toxin, 1.12 versus 0.63 and 0.95 versus $0.50)$. Virtually all of this enhancement of enterotoxin fluid response resided in the purified alpha-casein fraction.

\section{Abbreviation}

$\mathrm{V} / \mathrm{L}$, volume to length of loop ratio

Numerous gram-negative bacteria cause diarrhea by producing an enterotoxin that induces fluid loss into the intestine. Vibrio cholerae is the prototype for enterotoxin-induced disease, but milder forms can be induced by a wide variety of coliforms, including $E$. coli and Klebsiella sp. $(9,11,12)$. Although toxigenic
$E$. coli diarrhea is seldom fatal in adults, its effect on the neonate can be devastating. $(2,14,20)$. Clinically, the effects of these bacterial intoxications can be either ameliorated or exacerbated by multiple factors, one of which is secretory IgA directed against enterotoxin (19). These protective factors in breast milk may confer resistance to diarrhea in infants receiving mother's milk in underdeveloped countries (8).

While studying this protective effect of breast milk, we examined other milk proteins for their effect on enterotoxin-induced diarrhea. A number of bovine proteins were examined, and no additional factors were found that were specifically protective. We found that there is one milk protein, alpha-casein, present in large amounts in cow's milk that has a deleterious effect on intestine exposed to very small quantities of enterotoxin.

\section{MATERIALS AND METHODS}

Proteins. Highly purified Vibrio cholerae enterotoxin (Schwarz Mann, Orangeburg, NY, Lot BZ 2487) was initially suspended at a concentration of $10 \mu \mathrm{g} / \mathrm{ml}$ in phosphate buffered saline and stored at $4^{\circ} \mathrm{C}$. Before use, it was diluted in phosphate buffered saline to a concentration of either $10 \mathrm{ng}$ or $100 \mathrm{ng} / \mathrm{ml}$. Bovine casein hydrolysate (Sigma, St. Louis, MO, Lot 59B21000), bovine casein (Pentex, Kankakee, IL, Lot 96-005-1), bovine Beta lactoglobulin A (Pentex, Lot 96-003), bovine Beta lactoglobulin B (Pentex, Lot 96-004), bovine lactalbumin (Nutritional Biochemicals, Chagrin Falls, $\mathrm{OH}$ ), and bovine gamma globulin (Schwarz Mann, Lot Y3145) were dissolved in phosphate buffered saline at a concentration of $10 \mathrm{mg} / \mathrm{ml}$ just before use.

Isolation of human casein. One liter of pooled human breast milk was collected via breast pump from 15 normal nursing mothers at University Hospitals, Cleveland, $\mathrm{OH}$. The milk was 
defatted by centrifuging at $9000 \mathrm{rpm}$ for $60 \mathrm{~min}$ and concentrated by vacuum dialysis against normal saline to $300 \mathrm{ml}$. Casein was prepared from this skim, concentrated milk by slow acidification to $\mathrm{pH} 3.0$ with glacial acetic acid. The $\mathrm{pH}$ was readjusted to $\mathrm{pH}$ 4.0 with $1 \mathrm{~N} \mathrm{NaOH}$. The casein precipitate was removed by centrifugation at $9000 \mathrm{rpm}$ for $60 \mathrm{~min}$. The semi-solid slurry was suspended in distilled water and centrifuged at $5000 \mathrm{rpm}$ for 30 min. The pellet was resuspended in distilled water and thoroughly dialyzed against two changes of phosphate buffered saline. The casein solution was then lyophilized and dissolved in phosphate buffered saline $(10 \mathrm{mg} / \mathrm{ml})$ just before use.

Purification of alpha-casein. The proteins in bovine casein were fractioned into the alpha and non-alpha-portions by virtue of their differing charges. Alpha-casein was separated from the remainder of the caseins by DEAE cellulose for exchange chromatography (21) using an ascending salt gradient and descending pH gradient (Fig. 1 A). The high positive charge of bovine alphacasein causes it to bind preferentially to the negatively charged diethylaminoethyl groups and it can be eluted in pure form (a single band on polyacrylamide gel electrophoresis, Fig. 1B).

Pure alpha-casein and the mixture of non-alpha-caseins were tested at a concentration of $10 \mathrm{mg}$ in the rabbit intestinal loop with a low dose of enterotoxin (10 ng, less than 1 ED50).

Rabbit ileal loop assays. Intestinal loops were prepared by Sack's modification of the method of Kasai and Burrows (10, 15). New Zealand white, weanling, male rabbits, weighing 1.5$2.4 \mathrm{~kg}$ were fasted overnight before use. They were anesthetized with sodium pentobarbital $(25 \mathrm{mg} / \mathrm{kg}$ IV) and ether. The small intestine was ligated into $3-5-\mathrm{cm}$ loops. $V$. cholerae toxin (10 or $100 \mathrm{ng}$ ) was incubated with $1 \mathrm{ml}$ of $10 \mathrm{mg} / \mathrm{ml}$ of the previously mentioned protein solutions for $60 \mathrm{~min}$ at $37^{\circ} \mathrm{C}$ and injected with a 26 gauge needle into the loops.

Eighteen hours later, the animals were sacrificed, and the intestines removed for study. The small intestine was photographed and examined for the presence of gross hemorrhage. The loops were drained into a syringe, the volume of fluid noted, and the length of the loop measured. The activity of the toxin or toxin-protein combinations was determined by the ratio of volume within the intestinal loop to the length of the loop. A V/L ratio of $>0.5$ is characteristic of enterotoxin activity.

Statistical analysis. Each set of experiments was analyzed by analysis of variance where the treatments were fixed, and the

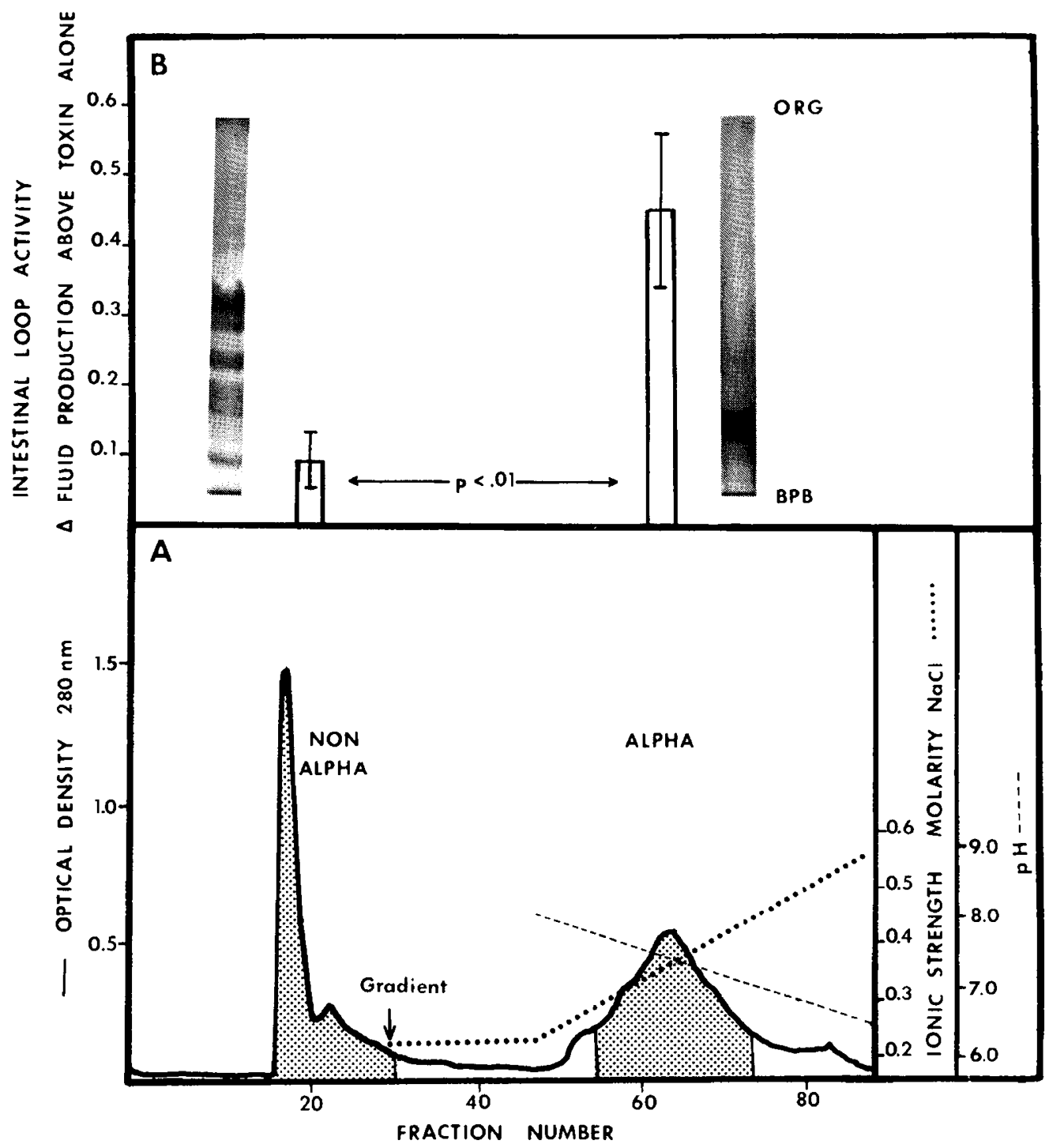

Fig. 1. Fluid production by intestine exposed to bovine casein fractions and enterotoxin. (A) DEAE chromatography of bovine casein. Optical densities of casein fractions obtained by DEAE exchange chromatography separation of whole bovine casein. The positively charged casein bound to the DEAE was eluted in pure form by an ascending salt gradient and a descending $\mathrm{pH}$ gradient. (B) Intestine exposed to $10 \mathrm{ng} V$. cholerae enterotoxin. The mean \pm S.D. of the change in fluid production above toxin alone was determined for both alpha- and non-alpha bovine casein. Superimposed upon this graph are photographs of the polyacrylamide gels of the electrophoresis of the casein fractions. ORG (origin), BPB (Bromphenol Blue-rapidly moving marker dye.) 
rabbits were considered a random variable (18). Scheffe's criterion was applied for multiple contrasts (16). lf, for example, a factor in analysis of variance is represented by $k+1$ levels with $\mathrm{k}$ degrees of freedom and is tested by an appropriate "error" term with $\mathrm{n}$ degrees of freedom, then Scheffe's criterion is $\mathrm{S}=$ $\sqrt{\mathrm{k} F(\mathrm{k}, \mathrm{n})}$ at the $\alpha$ level of type 1 error. The $\mathrm{F}(\mathrm{k}, \mathrm{n})$ is the tabular $\mathrm{F}$ value for this $\alpha$ level.

If the $F(k, n)$ computed in the analysis of variance does not exceed the tabular $F(k, n)$ for a given level of confidence, then the factor is considered not significant at this level of confidence. Scheffe has shown that under these conditions a $t$ test of any comparison of treatments will never yield a value in excess of $S$ (16).

If $F(k, n)$ is greater than tabular $F(k, n)$ so that the factor is considered significant at the $\alpha$ level, then one is free to do all the $t$-tests he devises using the $S$ as a criterion. Those that pass (i.e., $\mathrm{t}>\mathrm{S}$ ) are significant at the $\alpha$ level and those that fail are not significant at that level.

Ordinarily $t=\sqrt{\mathrm{F}}$, but it is apparent that Scheffe's criterion is a modified " $t$ " that is larger than the ordinary $t$ because $k$ is generally 1. Although $F(k, n)$ decreases with increasing $k$, the magnitude of the decrease of $F(k, n)$ is much smaller than the increasing $k$. There is some loss of power in using Scheffe's criterion but it gives a conservative estimate of what is and what is not significant when testing for relationships.

\section{RESULTS}

General description of intestinal loops. When the rabbit peritoneum was opened $18 \mathrm{~h}$ after surgery, the distended loops of bowel readily came into view. At this time the vascularity of the intestine was examined, and one rabbit with compromised blood flow to the intestine was discarded. Loops exposed to enterotoxin alone were tense and friable, but when the lumen was opened and the mucosa washed, no evidence of hemorrhage in the mucosa was observed. Occasionally, all the loops exposed to enterotoxin and casein were bloody. In these loops, although the vasculature was intact, blood was observed within the intestinal wall. Although the extent of bowel wall hemorrhage could not be easily quantitated, approximately $14 \%(4 / 29)$ of the animals in one series of experiments had enterotoxin-casein loops that were hemorrhagic. In these experiments, hemorrhage in loops containing purified enterotoxin alone was extremely rare. Histologic examination of these affected loops revealed hemorrhage within the tips of the villi and at the junction of the mucosa and submucosa. There was little evidence of an acute inflammatory infiltrate anywhere. The only histologic abnormalities in loops containing enterotoxin or enterotoxin and non-alpha-casein-rich proteins were thinning of the mucosa (associated with distension) and discharge of mucous from the goblet cells.

Fluid production by intestine exposed to milk proteins and enterotoxin. Because there are a large number of proteins in milk,

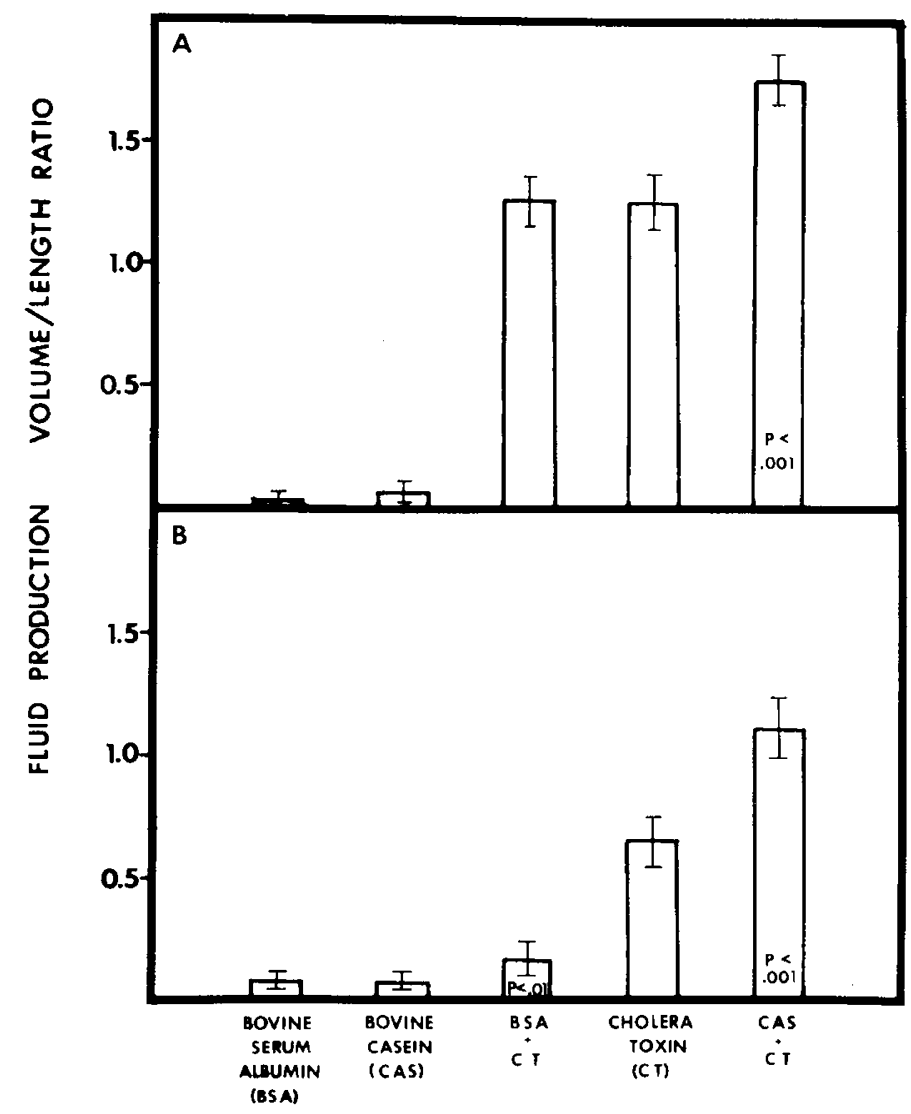

Fig. 2. Fluid production by intestine exposed to milk proteins and enterotoxin. (A.) Intestine exposed to $100 \mathrm{ng}$ of cholera enterotoxin. Fluid response/length of intestine for enterotoxin alone, protein alone (BSA or bovine casein) and the protein enterotoxin (100 $\mathrm{ng}$ ) combinations was determined in each of 12 rabbits. (mean \pm S.D.). (B.) Intestine exposed to $10 \mathrm{ng}$ of cholera enterotoxin. Fluid response/length of intestine with the above proteins was determined at a lower toxin dose (10 ng) in eight animals. (mean \pm S.D.).

the major classes of milk proteins were injected into rabbit loops to study their effect upon enterotoxin-induced fluid production. The activity of $100 \mathrm{ng}$ of toxin (>1 ED50) was not increased by bovine serum albumin (Fig. 2A), or bovine gamma globulin (Table 2). It should be remembered that human natural antibody to enterotoxin can easily inhibit this dose of enterotoxin (20). Bovine caseins in one experiment caused a $40 \%$ increase (Fig. $2 \mathrm{~A}$ ) in the fluid production induced by $100 \mathrm{ng}$ of enterotoxin (toxin $\mathrm{V} / \mathrm{L}, 1.30 \pm 0.13 \mathrm{~S}$.D. versus casein + toxin, $1.82 \pm 0.11$ S.D., $P<0.01$ ). In a second experiment bovine casein resulted in a $14 \%$ increase (Table 1 ) in fluid production induced by $100 \mathrm{ng}$

Table 1. Effect of various proteins upon fluid production induced by $100 \mathrm{ng}$ of $\mathrm{V}$. cholerae toxin

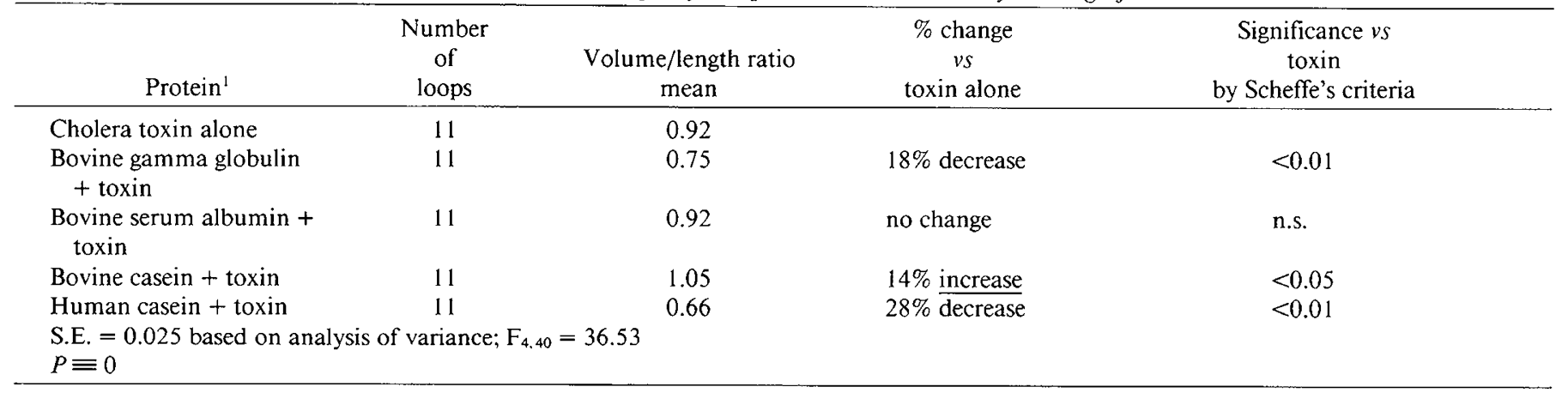

\footnotetext{
'Protein concentration, $10 \mathrm{mg} / \mathrm{ml}$.
} 
of enterotoxin ( $P<0.05$ by Scheffe's criterion). In no experiment did any other protein in the presence of enterotoxin induce fluid production above that of the saline controls. At the $100 \mathrm{ng}$ enterotoxin dose, there was no inhibitory effect of bovine serum albumin, but bovine gamma globulin and human casein each were able to reduce the expected fluid production (Table 1).

When milk proteins were added to very low dose enterotoxin (10 ng, approximately $1 / 10$ of an ED50) two types of effects were observed. All bovine non-casein proteins inhibited the action of cholera toxin by 77-90\% (Table 2 and Fig. 2B). Rather than inhibiting enterotoxin, in two experiments whole bovine casein caused an increase in fluid production by loops exposed to a suboptimal dose of enterotoxin (10 ng).

Figure $2 \mathrm{~B}$ demonstrates a $78 \%$ increase in fluid production/ intestine length (10 ng toxin, $0.63 \pm 0.10$ S.D. versus casein + toxin, $1.12 \pm 0.12$ S.D.) in nine animals exposed to low dose toxin and casein. An increase of $90 \%$ was noted in the second experiment (Table 2). Hydrolyzed casein failed to increase enterotoxin induced fluid production (Table 2 ).

Effect of enterotoxin and various doses of bovine caseins upon the intestine. In order to determine whether this casein-enterotoxin effect occurs at physiologically relevant casein concentrations, a casein dose-response curve was run at a constant enterotoxin dose of 10 ng. As demonstrated in Figure 3, there was not a striking relationship between casein dose and response in 14 animals; $100 \mu \mathrm{g}$ of casein caused a $72 \%$ increase in enterotoxininduced fluid response whereas $10 \mathrm{mg}$ of casein caused a $134 \%$ increase. All concentrations of casein tested with enterotoxin yielded significantly more fluid than toxin alone, and they were not statistically different from each other. Very small amounts of whole casein $(100 \mu \mathrm{g})$ were able to increase the fluid response.

Effect of enterotoxin and purified casein upon the intestine. Human casein, which has no alpha-casein, did not have the same effect on enterotoxin-exposed intestine as alpha-casein-rich bo-

Table 2. Effect of various bovine milk proteins upon fluid production induced by $10 \mathrm{ng}$ (less than 1 ED $D_{50}$ ) of $\mathrm{V}$. cholerae enterotoxin

\begin{tabular}{|c|c|c|c|c|}
\hline Protein $^{1}$ & $\begin{array}{l}\text { Number of } \\
\text { loops }\end{array}$ & $\begin{array}{l}\text { Volume/length ratio } \\
\text { mean }\end{array}$ & $\%$ change & $\begin{array}{c}\text { Significance } v s \\
\text { cholera toxin alone by } \\
\text { Scheffe's criterion at } \alpha=0.001\end{array}$ \\
\hline Cholera toxin alone & 9 & 0.498 & & \\
\hline $\begin{array}{l}\text { Alpha lactalbumin }+ \\
\text { toxin }\end{array}$ & 9 & 0.051 & $90 \%$ decrease & $<0.001$ \\
\hline $\begin{array}{l}\text { Beta lactoglobulin } A+ \\
\text { toxin }\end{array}$ & 9 & 0.053 & $90 \%$ decrease & $<0.001$ \\
\hline Serum albumin + toxin & 9 & 0.117 & $77 \%$ decrease & $<0.001$ \\
\hline $\begin{array}{l}\text { Hydrolyzed casein }+ \\
\text { toxin }\end{array}$ & 9 & 0.098 & $80 \%$ decrease & $<0.001$ \\
\hline \multicolumn{5}{|c|}{$\begin{array}{l}\text { S.E. }=0.0248 \text { for analysis of variance; } F_{6.48}=189.96 \\
P \equiv 0\end{array}$} \\
\hline
\end{tabular}

\footnotetext{
${ }^{1}$ Bovine proteins were used at a concentration of $10 \mathrm{mg} / \mathrm{ml}$.
}

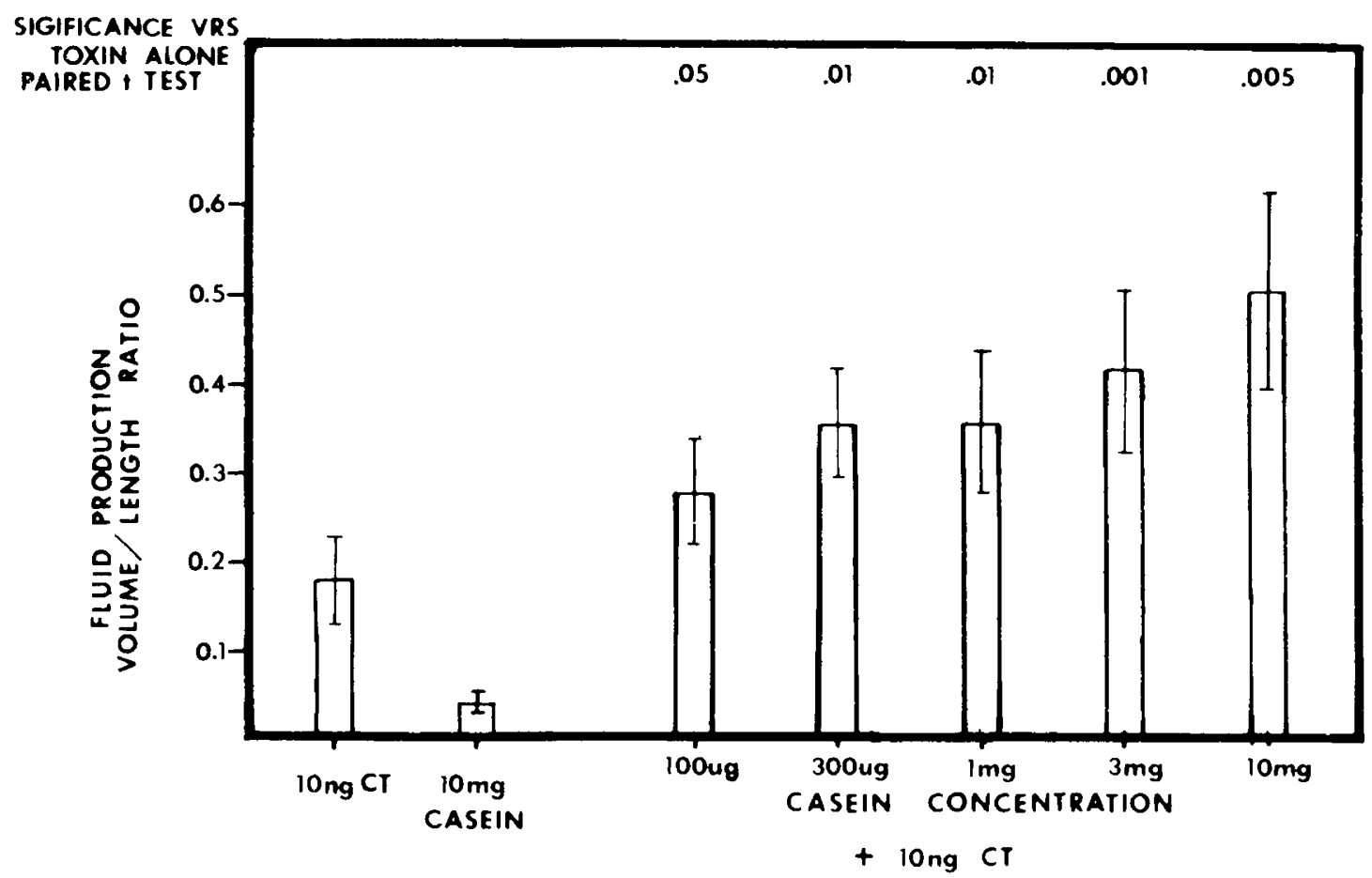

Fig. 3. Casein dose response curve. Fluid response/length of intestine was determined in each of 14 rabbits comparing casein-toxin loops to loops containing toxin alone (mean \pm S.D.). 
vine casein (Table 1). The bovine alpha-casein fraction exhibited increased fluid production in the enterotoxin exposed intestine whereas the bovine non-alpha-fraction did not.

Alpha-casein caused a strong, consistent increase in fluid production in six rabbits (Fig. 1B). In combination with enterotoxin, non-alpha-caseins caused a slight but not significant increase in fluid production. This non-alpha-casein-induced increase was significantly less than that achieved with pure alpha-casein $(P<$ $0.01)$.

\section{DISCUSSION}

In vivo, purified enterotoxin and bovine casein interacted to increase fluid production in the small intestine. We hypothesize that if the casein-enterotoxin interaction is operant in humans, individuals in the following two groups would be most affected.

(1) Individuals in underdeveloped countries, afflicted with diarrhea caused by an enterotoxigenic organism $(6,7)$ could suffer exacerbation of the diarrhea if the intestinal transit time is rapid enough to allow inadequate digestion of cow's milk protein.

(2) Bottle-fed infants receive the majority of their protein intake as casein from cow's milk. The preterm infant has well defined deficiencies in digesting fats $(13,17)$ and disaccharides $(1,4)$ and may have difficulties in digesting protein. If a preterm infant is colonized with an organism that normally produces insufficient amounts of enterotoxin to cause fluid production, then the presence of undigested casein in the ileum might induce gastrointestinal symptoms.

The mechanism of interaction between cholera enterotoxin and bovine casein is not clear. The molecular weight, solubility, and other characteristics of proteins are very similar in the alphacasein and non-alpha-casein fractions of bovine casein. The major difference is electrical charge. The casein molecule may alter the receptor sites for enterotoxin, thereby promoting attachment and increased fluid response.

The enterotoxins from Vibrio cholerae and $E$. coli are very similar in their structure and modes of action (5). A similar interaction may occur with enterotoxin from $E$. coli and casein ( $E$. coli enterotoxin is not currently commercially available to test in this system). Cushing (3) recently reported an outbreak of necrotizing enterocolitis associated with $E$. coli enterotoxin (3). We speculate that very small amounts of enterotoxin may be potentiated by dietary bovine casein and may help to explain some of the outbreaks of necrotizing enterocolitis in preterm infants.

There are three ways that enterotoxin can react with milk proteins. First, the natural antibodies in human milk can bind and inactivate toxin preventing diarrhea. This interaction occurs over a wide range of milk and toxin doses. Second, at extremely low enterotoxin doses $(10 \mathrm{ng})$, most bovine milk proteins and human casein seem to inactivate enterotoxin [although they have no effect on the doses of toxin (100 ng) usually used in rabbit ileal loop experiments]. Last, bovine casein exacerbates enterotoxin-induced gut-fluid distension. This increase in enterotoxin- induced fluid production occurred over a variety of casein and enterotoxin concentrations. Activity appeared to reside almost exclusively in the bovine alpha-casein, a protein absent from human breast milk. Associated with this increased fluid production was bowel wall hemorrhage in some animals; thus, in a small bowel exposed to bovine milk proteins we envision a picture of fluid production and hemorrhage induced by amounts of enterotoxin (10 $\mathrm{ng}$ ) that are normally without effect in bowel containing human breast milk.

\section{REFERENCES AND NOTES}

1. Abdo-Bassols, F., Lifshitz, F., and DelCastrillo, E. D.: Transient lactose intolerance in premature infants. Pediatrics, 48:816 (1971).

2. Boyer, K. M., Peterson, N. J., and Farzaneh, I. el al.: An outbreak of gastroenteritis due to E. coli 0142 in a neonatal nursery. J. Pediatr. 86: 919 (1975).

3. Cushing, A. $\mathrm{H}$ : Necrotizing enterocolitis with Escherichia coli heat-labile enterotoxin. Pediatrics, 71:626 (1983).

4. Dahlquist. A. and Lindberg. T.: Fetal development of the small-intestinal disaccharidase and alkaline phosphatase activities in the human. Biol. Neonate, 9: 24 (1966).

5. Field, M.: Modes of action of entertoxin from vibrio cholerae and Escherichia coli. Rev. Infect. Dis., 1: 918 (1979).

6. Gorbach, S. L., Kein, B. H. and Evans, D. G.: Travelers' diarrhea and toxigenic E coli. N. Engl. J Med., 292:933-936 (1975).

7. Gorbach. S. L. and Khurana, C. M.: Toxigenic Escherichia coli, a cause of infantile diarrhea in Chicago. N. Engl. J. Med., 287: 791 (1975),

8. Gordon, J. E. Guzman. M. A.. Ascoli. W., and Schrimshaw, N. S.: Acute diarrheal disease in less developed countries 2. Patterns of epidemiological behavior in rural Guatemalan villages. Bull. W. H. O., 31: 9 (1964).

9. Gross, R. J., Rowe B., Henderson, A., et al.: A new Escherichia coli 0-group 0159, associated with outbreaks of enteritis in infants. Scand. J. Infect. Dis. 8: 195 (1976).

10. Kasai, G. J. and Burrows, W.: The titration of cholera toxin and antitoxin in the rabbit ileal loop. J. Infect. Dis., 116: 606 (1966).

11. Klipstein. F. A. and Engert, R. F.: Purification and properties of Klebsiella pneumoniae heat-stable enterotoxin. Infect. Immun., [3: 378 (1976).

12. Mandel, D. H., Anselmo, C. R., and Wishnow, R. M.: Factors influencing heat labile Escherichia coli enterotoxin activity. Infect. Immun.. 14: 383 (1976).

13. Norman A Strandvik, B and Ojamae O : Bile acids and pancreatic enzymes during absorption in the newborn. Acta Paediatr. Scand., 61: 571 (1972)

14. Olarte, J. and Ramos-Alvarez, M.: Epidemic diarrhea in premature infants. Am. J. Dis. Child, 109:436 (1965)

15. Sack, R. B., Gorbach, S. L., Banwell, J. G.: Enterotoxigenic Escherichia coli isolated from patients with severe cholera-like disease. J. Infect. Dis., I23 378 (1971).

16. Scheffe', H.: The Analysis of Variance. (Wiley, New York 1959).

17. Signer, E., Murphy, G. M., Edkins, S., et al: The role of bile salts in the fat malabsorption of premature infants. Arch. Dis. Child 49: 174 (1974).

18. Steel, R. G. and Torrie, J. H.: Principles and Procedures of Statistics 2nd Ed. (McGraw-Hill, New York, 1980).

19. Stoliar, O. A., Pelley, R. P., Kaniecki-Green, E., et al: Secretory IgA against enterotoxins in breast milk. Lancet. 12: 1258 (1976).

20. Wheeler, W. L.: Spread and control of Escherichia coli diarrheal disease. Ann N.Y. Acad. Sci. 66:112 (1956).

21. Yaguchi M. and Rose, D.: Chromatographic separation of milk proteins. A review. J. Dairy Sci., 54: 1725 (1971).

22. Technical assistance was supplied by Evelyn Kanecki Green and statistical analysis was assisted by F. S. Green. III. Department of Biometry. The authors thank Bonnie Short for preparation of this manuscript.

23. Requests for reprints should be addressed to: Dr. David A. Clark, Assistant Professor of Pediatrics. Upstate Medical Center, 750 East Adams St., Syracuse, NY 13210

24. Received for publication September 8, 1980

25 . Accepted for publication July 6,1983 . 